\title{
Cloning of rat interleukin 11 and interleukin 11 receptor alpha chain and analysis of their expression in rat uterus in the peri-implantation period
}

\author{
R. Li, L. Hartley and L. Robb* \\ The Walter and Eliza Hall Institute of Medical Research and the Cooperative Research Centre \\ for Cellular Growth Factors, PO Royal Melbourne Hospital, Victoria 3050, Australia
}

\begin{abstract}
Studies in mice have shown that interleukin 11 (IL-11) signalling is required for female fertility. In the absence of IL-11, decidualization is markedly retarded and implantation fails. IL-11 acts via a heterodimeric receptor composed of a ligand-specific receptor $\alpha$ chain (IL-11R $\alpha$ ) and the signalling moiety gp130. This study reports the cloning of genes encoding rat IL-11 and IL-11R $\alpha$. RNase protection was used to demonstrate that expression of IL11 is upregulated in the rat uterus at the initiation of implantation at 5.5 days after mating. Expression of the
\end{abstract}

genes encoding the two receptor components, IL11Ra and gp130, did not change throughout the peri-implantation period. In situ hybridization studies revealed that, as in mice, expression of IL-11 was high in the primary decidual zone at the time of the attachment reaction, whereas IL11Ra was expressed throughout primary and secondary decidua. Conservation of the temporal and spatial expression of IL-11 and IL-11R $\alpha$ in the uterus of the mouse and rat during the peri-implantation period will facilitate future studies investigating the role of IL-11 in fertility.

\section{Introduction}

Interleukin 11 (IL-11) is a cytokine that is active on a range of different types of cell. Its effects include stimulation of haematopoietic progenitors, anti-inflammatory actions, effects on bone remodelling and induction of acute phase protein secretion by the liver (Du and Williams, 1997; Schwertschlag et al., 1999). Recombinant human IL-11 (rhIL-11) has been licensed as a biopharmaceutical for the treatment of post-chemotherapy-induced thrombocytopaenia. Studies on a variety of animal models have indicated that rhIL-11 is efficacious in treating acute and chronic inflammation disorders, such as inflammatory bowel disease (Peterson et al., 1998), hyperoxia and radiationinduced lung damage (Redlich et al., 1996; Waxman et al., 1999), sepsis (Barton et al., 1996; Chang et al., 1996; Opal et al., 1998), and graft versus host disease (Hill et al., 1998; Teshima et al., 1999).

IL-11 is a member of a family of cytokines that includes IL-6, leukaemia inhibitory factor (LIF), oncostatin M, cardiotropin 1 and ciliary neurotrophic growth factor. Members of this cytokine family signal via a high affinity receptor complex composed of a ligand binding $\alpha$ subunit and a common signal transducing subunit, gp130. IL-11 binds to a complex of IL-11 receptor $\alpha$ (IL-11R $\alpha$ ) and gp130. In mice, a locus encoding a second murine IL-11R $\alpha$ chain (IL11Ra2) has been identified. In contrast to the gene encoding IL-11R $\alpha$ (IL11Ra), which is expressed ubiquitously, expression of the gene encoding the second

*Correspondence

Email: robb@wehi.edu.au receptor is restricted to lymphoid tissues and testis (Bilinski et al., 1996; Robb et al., 1996, 1997).

Mice with a null mutation of the gene encoding IL-11R $\alpha$ revealed a key role for IL-11 in the fertility of female mice. In IL-11R $\alpha$ null female mice, the uterine decidualization reaction that occurs after implantation was defective, causing embryos to die at about day 8 (Robb et al., 1998). In another study, mice homozygous for a hypomorphic IL 11 Ra allele had a retarded decidualization response, in which the decidua degenerated before the formation of a chorioallantoic placenta (Bilinski et al., 1998). Expression of IL-11 in the pregnant uterus was upregulated at the time of embryo implantation and in situ hybridization revealed high expression of IL-11 in cells of the primary decidual zone (Robb et al., 1998). The presence of IL-11 mRNA (IL11) and IL-11 protein in human endometrial tissues has been demonstrated. In agreement with studies in mice, immunoreactive IL-11 was at a maximum concentration in decidual cells (Dimitriadis et al., 2000).

Uterine receptivity and the uterine stromal cell decidualization response are essential for the successful establishment and maintenance of pregnancy. The decidualization process, in which uterine stromal cells undergo transformation in response to the implanting blastocyst, is particularly marked in species such as rats and humans in which placentation is characterized by extensive invasion of trophoblast cells. Historically, the morphological changes that occur during decidualization have been characterized most extensively in the laboratory rat (De Feo, 1967; O'Shea et al., 1983). More recently, Gu and Gibori (1995) examined the endocrine functions and gene expression profiles of rat decidual cells. The present 
study reports on cloning of cDNAs encoding rat IL-11 and $\mathrm{IL}-11 \mathrm{R} \alpha$ and examines the expression of $I L-11$ in the rat uterus as it undergoes decidualization in response to the implanting blastocyst.

\section{Materials and Methods}

\section{Cloning of rat IL-11 and IL11Ra genes}

A Sprague-Dawley rat testis cDNA library (Stratagene, La Jolla, CA) was screened with radiolabelled oligonucleotides for murine $I L-11$ to isolate cDNAs encoding rat $I L-11$. Total RNA was prepared from rat testis using Trizol (Life Technologies, Grand Island, NY) and 5' RACE was performed using the 5' RACE Kit (Life Technologies) to obtain the $5^{\prime}$ end of the cDNA. The nested gene-specific primers used were: 5'-TTGTGGTCTCCATCAGCTGGGAAAT-3', 5'-GAGGGTCTGAAGACACTCGAGGGG-3' and 5'-GCCAGAGGCTCAGCACCACCAGGA-3'. After nested amplification, PCR products were cloned into pGEM-T Easy (Promega, Madison, WI). The rat testis cDNA library was screened at reduced stringency with radiolabelled cDNA fragments of murine IL11Ra to isolate rat IL11Ra CDNAs. Purified cDNA clones and 5' RACE products were sequenced using the Prism Ready Reaction Dye Deoxy Terminator Cycle Sequencing Kit (Applied Biosystems, Foster City, CA) on a 373A DNA sequencer (Applied Biosystems).

\section{Northern blot analysis}

Total RNA was prepared from rat tissues using Trizol (Life Technologies) and poly(A+) RNA was selected using oligo(dT) cellulose (Roche Diagnostics $\mathrm{GmbH}$, Mannheim). Northern blot analysis was performed as described by Robb et al. (1996). The filters were hybridized with a $\left[\alpha_{-}{ }^{32} P\right] d A T P-$ labelled 700 bp IL-11 cDNA probe or with a 850 bp IL 11Ra cDNA probe. Each filter was then stripped and rehybridized with a radiolabelled GAPDH cDNA fragment.

\section{Collection of rat tissues}

Adult (8-12 week old) female Wistar rats were mated and then killed at timed intervals by $\mathrm{CO}_{2}$ inhalation followed by cervical dislocation for collection of the uterus. Midday of the day on which the vaginal plug was detected was considered as day 0.5 after mating. Samples for RNA preparation were frozen in liquid nitrogen and stored at $-70^{\circ} \mathrm{C}$ before total RNA preparation. For uterine samples collected at days 2.5-4.5 after mating, an oviduct or uterine horn was flushed to ascertain the presence of fertilized eggs or blastocysts. For uterine samples collected at day 5.5 after mating, the presence of implantation sites was ascertained at the time of collection by administering $200 \mu \mathrm{l}$ of a $1 \%$ $(\mathrm{w} / \mathrm{v})$ solution of Chicago Sky Blue via the tail vein $5 \mathrm{~min}$ before the animals were killed. In addition, a portion of one uterine horn was cut into serial sections and subsequently examined using a microscope to confirm the presence of implantation sites. All procedures were approved by the Animal Ethics Committee of the Royal Melbourne Hospital.

\section{RNase protection analysis}

RNase protection analyses were performed using the RPAIII Kit (Ambion Inc., Austin, TX) as described by Robb et al. (1998). Ten micrograms of RNA was used in each hybridization reaction. Two independent sets of uterine tissues from different females with a vaginal plug were collected and examined for gene expression at each of the 15 time points studied in this analysis. Results were comparable between the two sets of tissues at all time points. All cDNA fragments used as riboprobes were cloned into pBluescript SK. The rat $I L-11$ riboprobes were two 257 bp (nucleotides 173-430 and nucleotides 321-578) cDNA fragments. The rat IL11Ra riboprobes were $242 \mathrm{bp}$ (nucleotides 666-908) and $319 \mathrm{bp}$ (nucleotides 845-1164) cDNA fragments. The rat LIF riboprobe was a 229 bp cDNA fragment (nucleotides 93-322, Genbank accession no. AB010275). The rat gp130 riboprobe was a 260 bp cDNA fragment (nucleotides 1571-1830, Genbank accession no. M92340). A 316 bp fragment of the rat GAPDH cDNA (Ambion), labelled to 50-fold lower specific activity, was used to estimate RNA loading.

\section{In situ hybridization}

Tissues were fixed in 4\% (w/v) paraformaldehyde and were dehydrated and embedded in paraffin wax. Adjacent sections ( $5 \mu \mathrm{m}$ in thickness) from three to six females with a vaginal plug were processed and hybridized with $\left[\alpha_{-}{ }^{33} \mathrm{P}\right]$ UTP-labelled sense and antisense riboprobes as described by Lyons et al. (1995). Similar results were obtained in experiments using sectioned uteri from different females with vaginal plugs. Both murine and rat $I L-11$ and IL11Ra riboprobes were used. In both cases, the murine and rat probes gave similar results, although, in general, background was lower with the rat probes.

\section{Results}

\section{Cloning of rat genes encoding $I L-11$ and $I L-11 R \alpha$}

Rat IL-11 cDNA clones were obtained by screening a rat testis cDNA library with oligonucleotides corresponding to conserved regions of the murine $I L-11 \mathrm{CDNA}$. The $5^{\prime}$ end of the cDNA was obtained using 5' RACE. A composite partial CDNA of 1264 nucleotides with an open reading frame of 600 nucleotides was obtained (Genbank accession no. AF34935). The deduced 199 amino acid sequence had 194 of $199(97 \%)$ shared identity with that of the murine sequence, and 170 of 199 (86\%) and 178 of $199(90 \%)$ shared identity with non-human primate and human IL-11 sequences, respectively (Fig. 1).

In humans, two $I L-11$ transcripts of 2.5 and $1.5 \mathrm{~kb}$ encode the same functional protein, whereas only a single 2 kb transcript was detected in mouse RNA (Paul et al., 1990; 

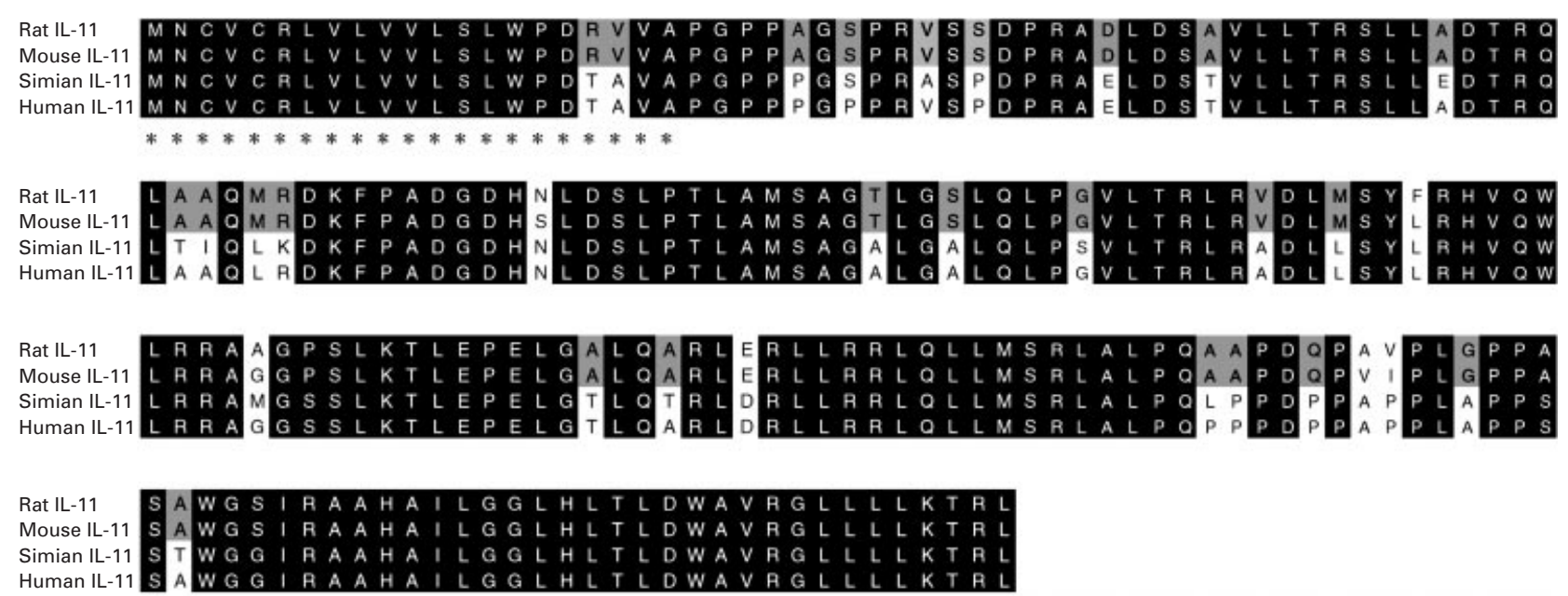

Fig. 1. The amino acid sequences of rat, mouse, non-human primate and human interleukin 11 (IL-11). Amino acids that are identical in all four species are shown as white lettering on black background, and amino acids conserved between mice and rats are shaded grey. The 21 amino acid leader sequence is indicated by asterisks. Genbank accession numbers are: rat, AF34935; mouse, U03421; monkey, M57766; human, M57765, X58377.

Kawashima et al., 1991; Morris et al., 1996). Northern blot analysis of poly $(\mathrm{A}+) \mathrm{RNA}$ from pregnant rat uterus revealed a single transcript of approximately $2 \mathrm{~kb}$ (Fig. 2).

Rat IL11Ra cDNA was obtained by screening a cDNA library of rat testis with a murine IL11Ra cDNA fragment. The cDNA clones obtained all encoded a single transcript. The composite rat IL11Ra cDNA was 1713 nucleotides and contained an open reading frame of 1296 nucleotides (Genbank accession no. AF347936). The deduced 430 amino acid sequence was aligned with that of human and murine IL-11R $\alpha$ (Fig. 3). The human and rat sequences shared identity at 346 of 430 residues $(80 \%)$, and the rat and murine sequences shared identity at 407 of $430(95 \%)$ residues. Northern blot analysis revealed a single $1.8 \mathrm{~kb}$ IL11Ra transcript in all tissues examined (Fig. 2).

\section{Expression of IL-11, IL11 Ra and gp130 during the peri- implantation period}

Total RNA was prepared from uteri of rats at sequential times after detection of a vaginal plug. Before implantation, the presence of blastocysts was confirmed by flushing the lumen of a portion of each specimen. Implantation sites were detected in uterine samples collected at day 5.5 after mating using the blue dye reaction (Psychoyos, 1973). RNase protection studies were performed using $10 \mu \mathrm{g}$ total RNA. IL11 transcripts were detected at a low concentration in the uteri of virgin rats and at days 0.5-4.5 after mating, whereas at day 5.5 after mating, IL-11 expression was markedly upregulated (Fig. 4). Expression of $I L-11$ remained high up to day 9.5 after mating. As in mice, expression of LIF preceded that of $I L-11$, and was detectable at low concentrations in the uterus of virgin rats and both before and after implantation. LIF expression was high in uterine samples collected at days 9.5-11.5 after mating, but decreased thereafter. Expression of
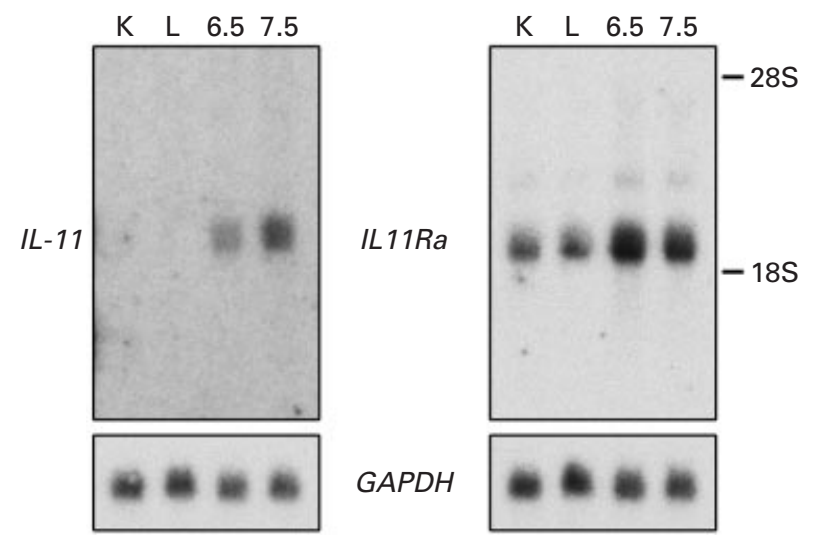

Fig. 2. Northern blot analysis of expression of genes encoding interleukin 11 (IL-11) and interleukin 11 receptor alpha (IL11Ra). Poly $(\mathrm{A}+)$ RNA prepared from rat tissues was hybridized with a radiolabelled IL-11 or a IL11Ra CDNA probe. The northern blots were stripped and rehybridized with a radiolabelled cDNA fragment of rat GAPDH to assess RNA loading. K: kidney; L: liver; 6.5: pregnant rat uterus collected at day 6.5 after mating; 7.5: pregnant rat uterus collected at day 7.5 after mating. The positions of the $28 \mathrm{~S}$ and $18 \mathrm{~S}$ ribosomal bands are shown.

the two IL-11 receptor components, IL11Ra and gp130, was detected at all time points examined, although the expression of IL11Ra decreased after day 9.5 after mating. Similar results were obtained using different RNA samples and different IL11 and IL11Ra probes.

\section{Expression of IL-11 in the primary decidual zone}

An in situ hybridization analysis of uterine samples collected at days 0-11 after mating was performed using 


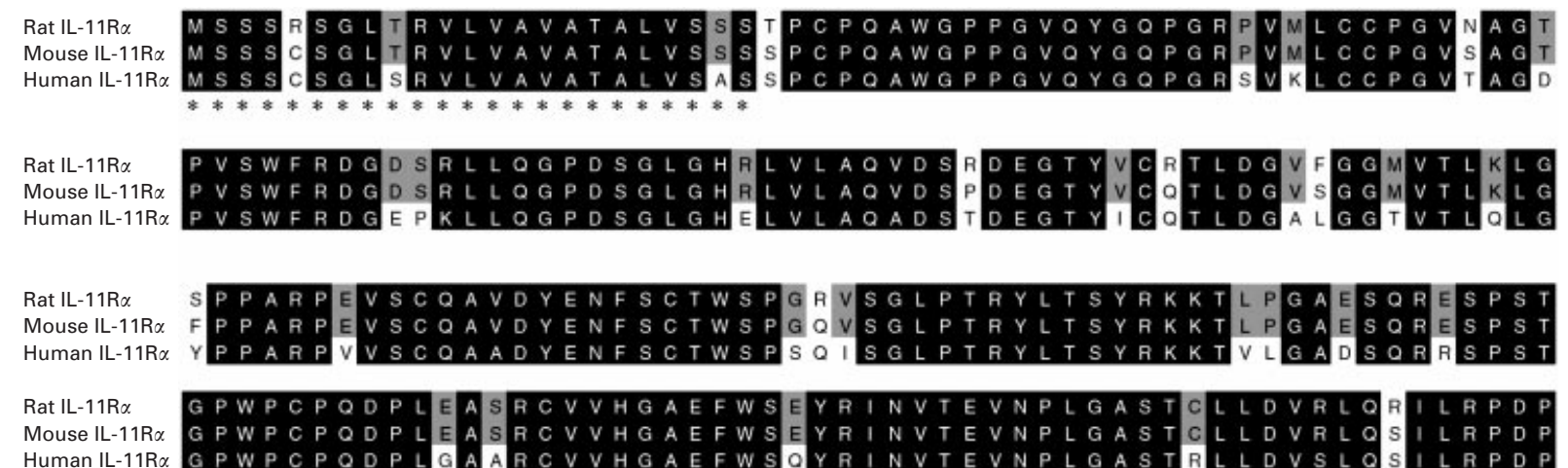

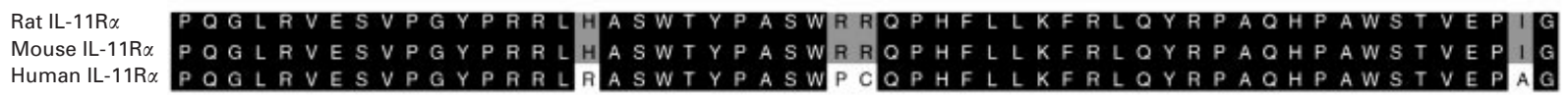

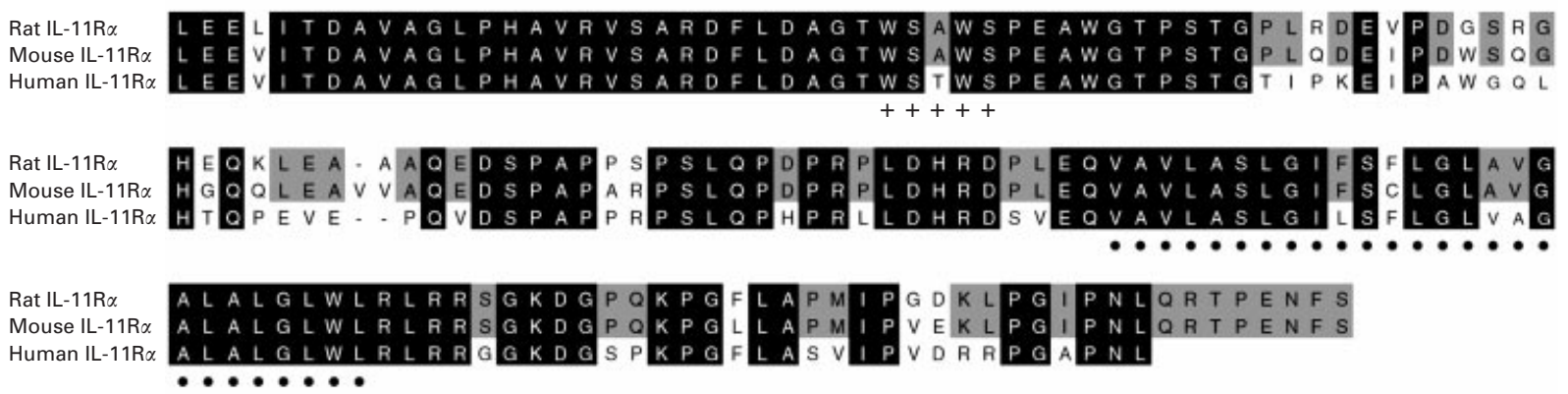

Fig. 3. The amino acid sequences of rat, mouse and human interleukin 11 receptor alpha (IL-11R $\alpha$ ). Amino acids that are identical in all three species are shown as white lettering on black background, and amino acids conserved between mice and rats are shaded grey. Gaps introduced to maximize the alignment are shown using dashes. Asterisks $(*)$ indicate the potential signal sequence, crosses (+) indicate the conserved WSXWS motif and dots (O) indicate the transmembrane region. Genbank accession numbers are: rat, AF347936; mouse, U14412, X98519; human, U32324, Z38102.

$\left[\alpha{ }^{3}{ }^{33}\right.$ P]UTP-labelled rat $I L-11$ probes to determine the spatial expression of IL-11 in the peri-implantation uterus. Expression of $I L-11$ was first detected in uterine samples collected at day 5.5 after mating. In all sections examined, expression of IL-11 was observed in the subepithelial primary decidual zone adjacent to the apposed blastocyst (Fig. 5). At later time points, expression of $I L-11$ was detectable at a low concentration throughout decidual tissues (not shown).

\section{Expression of IL11Ra in decidual tissue}

In situ hybridization of $\left[\alpha-{ }^{33} \mathrm{P}\right]$ UTP-labelled rat IL11Ra riboprobes to uterine sections collected at days 0-11 after mating was undertaken. Hybridization revealed a general increase in the expression of IL11Ra in both decidual and uterine tissues compared with adjacent sections hybridized with control sense riboprobes. In preimplantation uteri, expression of IL11Ra was low throughout the uterus. Day 5.5 after mating was the only time point at which a more localized pattern of expression was observed. At this time point, IL11Ra expression was highest in stroma adjacent to the luminal epithelium (Fig. 6a-C). Thereafter, widespread expression of IL11Ra was detected throughout decidual and non-decidual tissues (Fig. 6d-f).

\section{Discussion}

The composite nucleotide sequences of rat $I L-11$ and $I L$ $11 R a$ were determined by sequencing cDNA clones obtained by screening a rat testis cDNA library. Northern blot analysis revealed a single $2 \mathrm{~kb} / L-11$ transcript in the poly(A+) RNA prepared from pregnant rat uterus. In other studies, a single $2 \mathrm{~kb}$ transcript was detected in RNA prepared from a murine cell line, whereas a major 2.5 and a minor $1.5 \mathrm{~kb} / L-11$ transcript were observed in several human tissues (Paul et al., 1990; Kawashima et al., 1991; Morris et al., 1996). In humans, the two transcripts arise as a result of alternative use of two polyadenylation sites located within the 3' non-coding region of the gene (Paul et al., 1990). However, in mouse and rat tissues examined to date, it appears that there is only a single $I L-11$ transcript.

In the present study, cDNA clones encoding a second rat IL-11R $\alpha$ in a cDNA library prepared from rat testis were not obtained. Testis was the major site of expression of the 


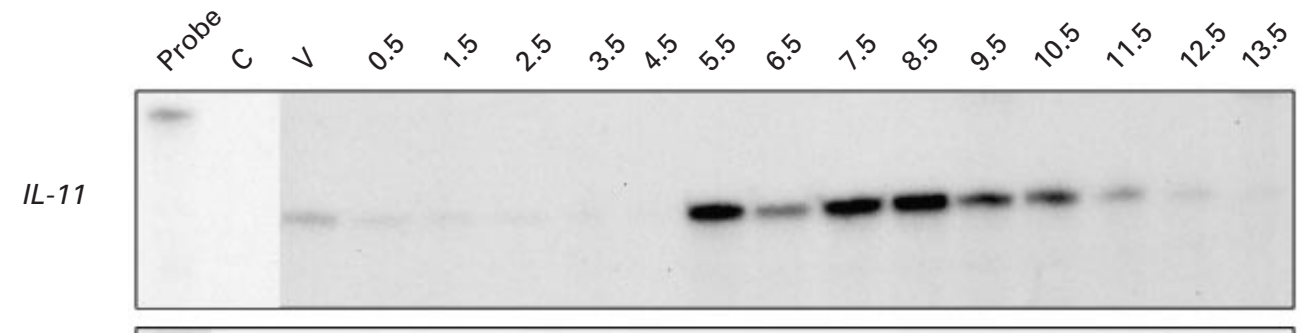

LIF

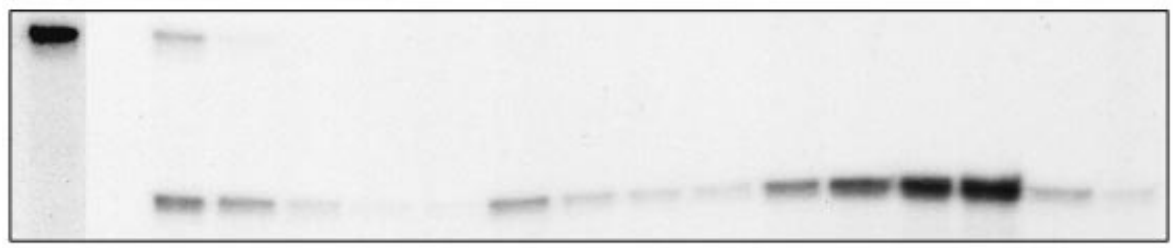

IL11Ra
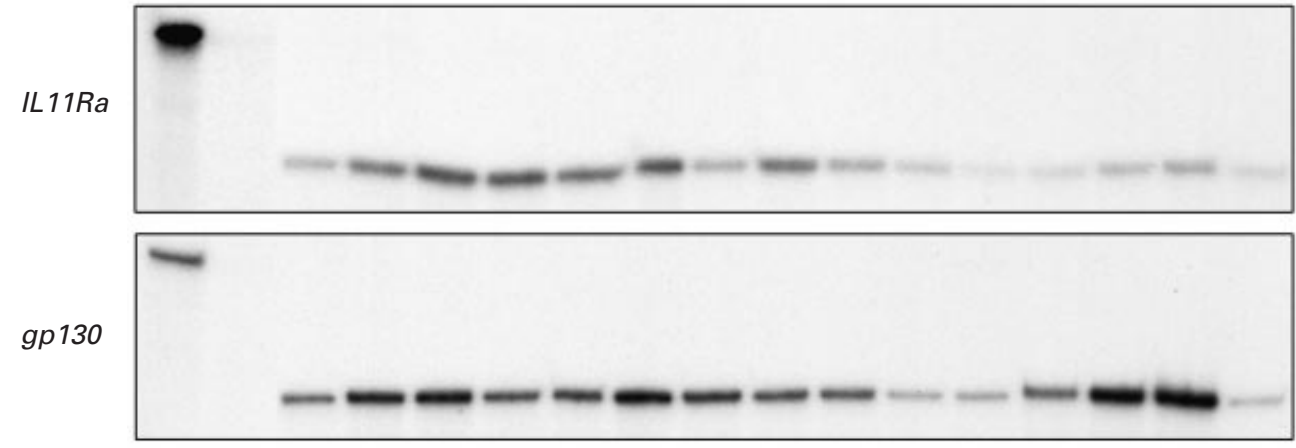

GAPDH

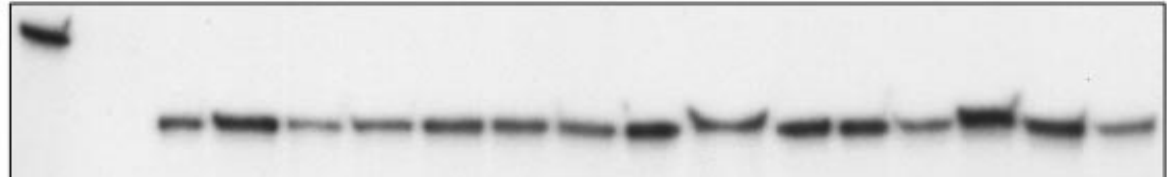

Fig. 4. RNase protection analysis of expression of genes encoding interleukin 11 (IL-11), leukaemia inhibitory factor (LIF), interleukin 11 receptor alpha (IL11Ra) and gp130 in virgin and pregnant rat uterus. Ten micrograms of total RNA was used in each hybridization reaction. A GAPDH riboprobe, labelled to 50-fold lower specific activity, was used to quantify the amount of RNA present. Probe: undigested, full-length probe; C: probe after RNase digestion; V: virgin; 0.5-13.5: days after mating.

second IL-11R $\alpha$ receptor in mice (Robb et al., 1997). The likely absence of the second receptor in rats is in accordance with previous observations that two, or in some cases multiple, IL11Ra loci arose in some inbred mouse strains as a result of a recent duplication event. Only a single locus encoding IL-11R $\alpha$ was found in humans (Nandurkar et al., 1996), in some inbred mouse strains (Robb et al., 1996) and in the wild mouse strain Mus spretus (L. Robb, unpublished).

Comparison of the predicted amino acid sequence of rat IL-11 with mouse, non-human primate and human IL-11 revealed that IL-11 was highly conserved among species. The 21 amino acid signal sequence was also conserved. Rat IL-11, like its human and murine equivalents, is a very basic protein, rich in proline and leucine and lacking cysteine residues and $\mathrm{N}$-glycosylation sites. The predicted amino acid sequence of rat IL-11R $\alpha$ also showed a high degree of shared identity among species. The conservation of IL-11 and IL-11R $\alpha$ homologues is in accordance with studies showing that rhIL-11 is active with target cells of both mice (Quesniaux et al., 1993) and rats (Yonemura et al., 1993).

The cloning of rat cDNAs encoding IL-11 and its receptor enabled the expression of these genes in the pregnant rat uterus to be studied by RNase protection. The levels of expression of the two receptor components, IL11Ra and gp130, were not significantly altered during the study period. IL-11 transcripts were detected at a low concentration in the uteri of virgin rats and in rat uteri collected at days $0.5-4.5$ after mating. At day 5.5 after mating, immediately after implantation, expression of $I L-11$ was upregulated. Expression of IL-11 was observed up to day 10.5 after mating, but decreased thereafter. In situ hybridization of uterine sections collected at day 5.5 after mating showed a marked localization of IL-11 to the primary decidual zone. This temporal and spatial pattern of expression of $I L-11$ and its receptors in the pregnant uterus was very similar to that observed in mice (Robb et al., 1998). In mice, IL-11 

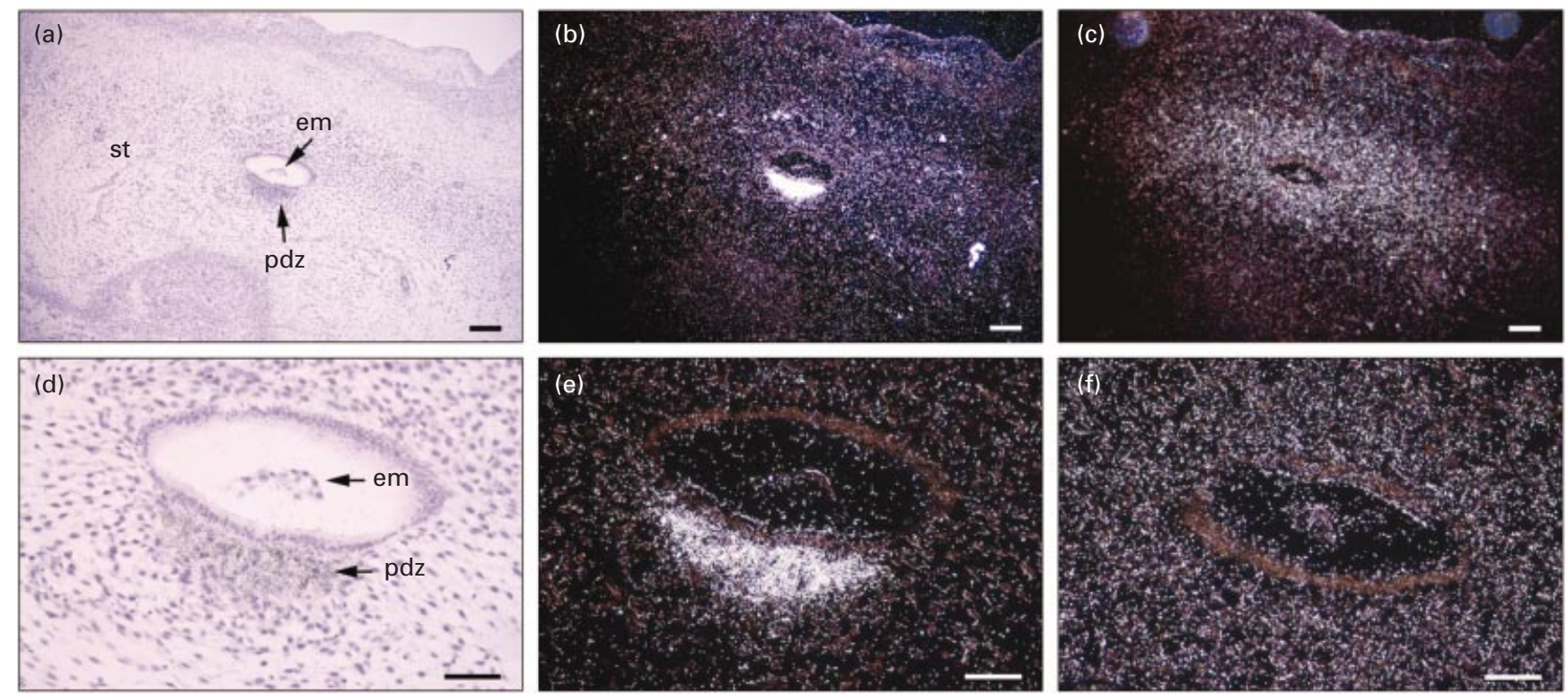

Fig. 5. Interleukin 11 (IL-11) expression in the primary decidual zone at day 5.5 after mating. Serial sections of rat uterus collected at day 5.5 after mating were hybridized with sense $(c, f)$ and antisense $(a, b, d, e)$ rat $I L-11$ riboprobes. Expression was restricted to the primary decidual zone, adjacent to the apposed blastocyst. (a,d) Light-field images; (b,c,e,f) dark-field images. em: embryo, pdz: primary decidual zone; st: uterine stroma. Scale bars represent $(\mathrm{a}-\mathrm{c}) 50 \mathrm{~nm}$ and $(\mathrm{d}-\mathrm{f}) 25 \mathrm{~nm}$.
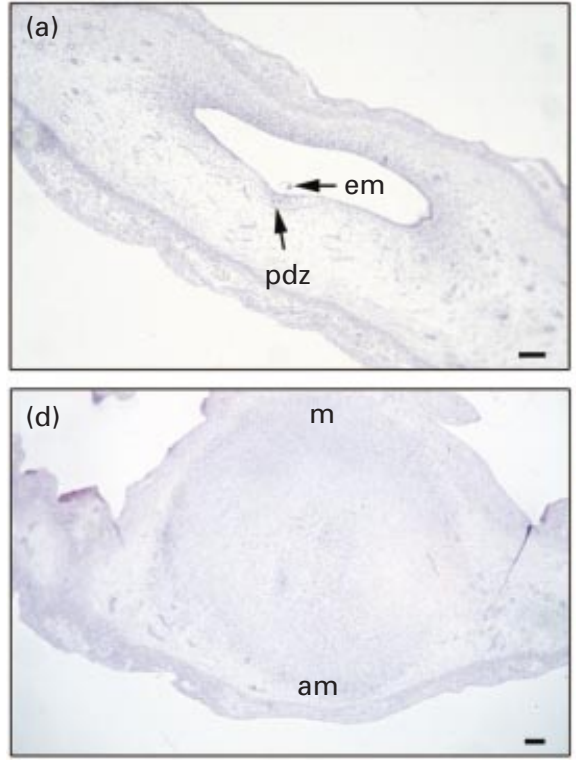
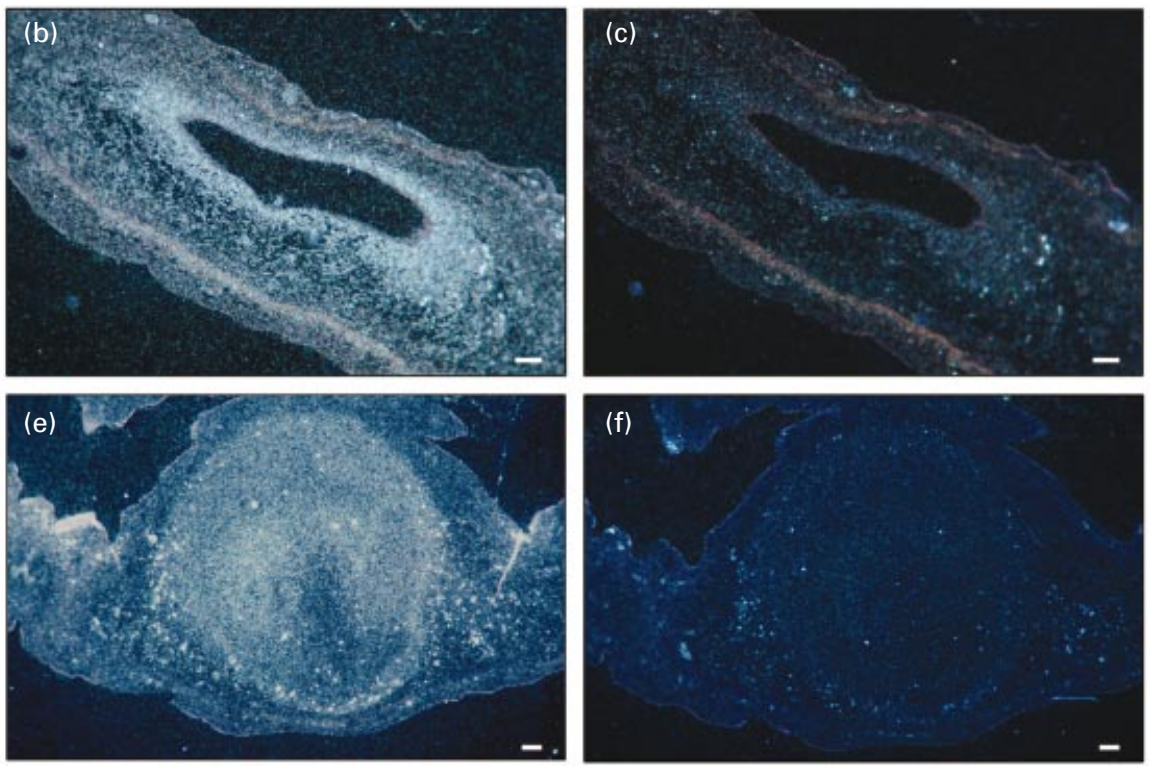

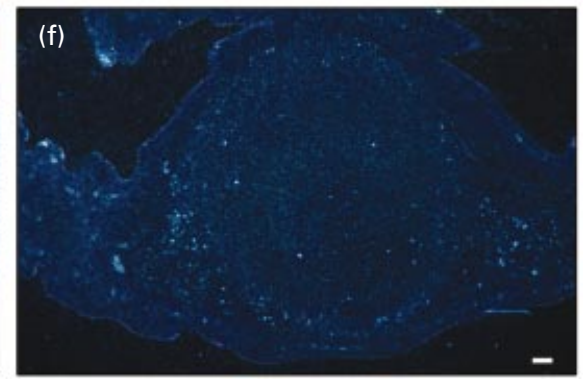

Fig. 6. Interleukin 11 receptor alpha (IL11Ra) expression in the pregnant rat uterus. Serial sections of rat uterus collected at day 5.5 after mating $(\mathrm{a}-\mathrm{c})$ and at day 6.5 after mating $(\mathrm{d}-\mathrm{f})$ were hybridized with sense $(\mathrm{a}, \mathrm{c}, \mathrm{d}, \mathrm{f})$ and antisense $(\mathrm{b}, \mathrm{e})$ rat IL11Ra riboprobes. At both times, expression of IL11Ra was higher throughout uterine and decidual tissues. (a,d) Light-field images; (b,c,e,f) dark-field images. am: antimesometrial decidua, m: mesometrial decidua, em: embryo; pdz: primary decidual zone. Scale bars represent $100 \mu \mathrm{m}$.

expression was regulated temporally in deciduomata (Robb et al., 1998). IL-11 expression in the decidual cells of mouse and rat uterus during the peri-implantation period indicates that the action of this cytokine may be linked to that of other implantation-specific genes induced by active blastocysts at the time of the attachment reaction. These genes include members of the epidermal growth factor-like growth factor family, COX-2 and LIF (Das et al., 1994, 1995, 1997; Chakraborty et al., 1996; Lim et al., 1997a, 1998; Song et al., 2000).

LIF expression was observed throughout the periimplantation period, preceding the increase in IL-11 
expression at day 5.5 after mating. LIF was detectable in the uterus from day 5.5 to day 9.5 after mating and increased at day 10.5 and day 11.5 after mating. This finding is in contrast to the pattern of LIF expression in mice, in which LIF expression is markedly upregulated at the time of implantation and decreases thereafter (Bhatt et al., 1991; Shen and Leder, 1992; Robb et al., 1998). In rats, the choriallantoic placenta is established at about day 10.5 after mating. LIF expression has been observed in murine placenta, but not in embryos, at day 9.5-12.5 after mating (Conquet and Brulet, 1990; Bhatt et al., 1991; Shen and Leder, 1992). The increase in LIF transcription in pregnant rat uterus at days 10.5 and 11.5 after mating may be due to expression in placenta; however, in situ hybridization studies would be required to confirm this contention.

Implantation relies on successful development of the embryo to the blastocyst stage and on steroid hormone priming of the endometrium to a receptive state (Cross et al., 1994; Lim et al., 1997b). At the site of implantation, the decidual reaction is initiated. The importance of decidualization for successful embryonic survival after implantation is well recognized. Although it has been established that decidualization is regulated, in part, by prostaglandins (Kennedy, 1994), other requirements for a normal decidual response to the implanting blastocyst are poorly understood. Results from this study have shown that, in mice, IL11 signalling is obligatory for this process, and recent work demonstrated the localization of IL-11 immunoreactive protein in human decidual cells and its expression in these cells before the upregulation of prolactin expression (Dimitriadis et al., 2000). The temporal and spatial pattern of expression of IL-11 in the rat uterus during the periimplantation period, as demonstrated in this study, supports the notion that this cytokine is involved in decidualization. The results also validate the use of rats as a model for future studies examining the use of $\mathrm{IL}-11$ receptor antagonists as contraceptive agents.

The authors are grateful to B. Borobakis for preparation of riboprobes. The authors would also like to thank to E. Dimitriadis and L. Salamonsen for working with them on the IL-11 story and for critically reading the manuscript; and T. Kennedy for his valuable comments on the manuscript. This research was supported by the National Health and Medical Research Council of Australia, The Contraceptive Research and Development (CONRAD) Program, USA and The Sylvia and Charles Viertel Charitable Foundation, Australia (LR).

\section{References}

Barton BE, Shortall J and Jackson JV (1996) Interleukins 6 and 11 protect mice from mortality in a staphylococcal enterotoxin-induced toxic shock model Infection and Immunity 64 714-718

Bhatt H, Brunet LJ and Stewart CL (1991) Uterine expression of leukaemia inhibitory factor coincides with the onset of blastocyst Proceedings National Academy of Sciences USA $8811408-11412$

Bilinski P, Hall MA, Neuhaus H, Gissel C, Heath JK and Gossler A (1996) Two differentially expressed interleukin-11 receptor genes in the mouse genome Biochemistry Journal 320 359-363
Bilinski P, Roopenian D and Gossler A (1998) Maternal IL-11R $\alpha$ function is required for normal decidua and fetoplacental development in mice Genes and Development 12 2234-2243

Chakraborty I, Das SK, Wang J and Dey SK (1996) Developmental expression of the cyclo-oxygenase- 1 and cyclo-oxygenase-2 genes in the peri-implantation mouse uterus and their differential regulation by the blastocyst and ovarian steroids Journal of Molecular Endocrinology 16 107-122

Chang M, Williams A, Ishizawa L, Knoppel A, van de Ven C and Cairo MS (1996) Endogenous interleukin-11 (IL-11) expression is increased and prophylactic use of exogenous IL-11 enhances platelet recovery and improves survival during thrombocytopenia associated with experimental group B streptococcal sepsis in neonatal rats Blood Cells, Molecules and Diseases 22 57-67

Conquet F and Brulet P (1990) Developmental expression of myeloid leukemia inhibitory factor gene in preimplantation blastocysts and in extraembryonic tissue of mouse embryos Molecular and Cellular Biology $103801-3805$

Cross JC, Werb Z and Fisher SJ (1994) Implantation and the placenta: key pieces of the development puzzle Science 266 1508-1518

Das SK, Wang XN, Paria BC, Damm D, Abraham JA, Klagsbrun M, Andrews GK and Dey SK (1994) Heparin-binding EGF-like growth factor gene is induced in the mouse uterus temporally by the blastocyst solely at the site of its apposition: a possible ligand for interaction with blastocyst EGF-receptor in implantation Development 120 1071-1083

Das SK, Chakraborty I, Paria BC, Wang XN, Plowman G and Dey SK (1995) Amphiregulin is an implantation-specific and progesterone-regulated gene in the mouse uterus Molecular Endocrinology 9 691-705

Das SK, Das N, Wang J, Lim H, Schryver B, Plowman GD and Dey SK (1997) Expression of betacellulin and epiregulin genes in the mouse uterus temporally by the blastocyst solely at the site of its apposition is coincident with the "window" of implantation Developmental Biology $190178-190$

De Feo VJ (1967) Decidualization. In Cellular Biology of the Uterus pp 191-290 Ed. RM Wynn. Appleton-Century-Crofts, Amsterdam

Dimitriadis E, Salamonsen LA and Robb L (2000) Expression of interleukin11 during the human menstrual cycle: coincidence with stromal cell decidualization and relationship to leukaemia inhibitory factor and prolactin Molecular Human Reproduction 6 907-914

Du XX and Williams DA (1997) Interleukin-11: review of molecular, cell biology and clinical use Blood $893897-3908$

Gu Y and Gibori G (1995) Isolation, culture and characterization of the two cell subpopulations forming the rat decidua: differential gene expression for activin, follistatin and decidual prolactin-related protein Endocrinology 136 2451-2458

Hill GR, Cooke KR, Teshima T, Crawford JM, Keith JC, Jr, Brinson YS, Bungard D and Ferrara JL (1998) Interleukin-11 promotes T cell polarization and prevents acute graft-versus-host disease after allogeneic bone marrow transplantation Journal of Clinical Investigation 102 115-123

Kawashima I, Ohsumi J, Mita-Honjo K, Shimoda-Takano K, Ishikawa H, Sakakibara S, Miyadai K and Takiguchi Y (1991) Molecular cloning of a cDNA encoding adipogenesis inhibitory factor and identity with interleukin-11 FEBS Letters 283 199-203

Kennedy TG (1994) Involvement of local mediators in blastocyst implantation. In Endocrinology of Embryo-Endometrial Interactions pp 183-194 Eds SR Glasser, J Mulholland and A Psychoyos. Plenum Press, New York

Lim H, Dey SK and Das SK (1997a) Differential expression of the erbB2 gene in the periimplantation mouse uterus: potential mediator of signaling by epidermal growth factor-like growth factors Endocrinology $\mathbf{1 3 8}$ 1328-1337

Lim H, Paria BC, Das SK, Dinchuk JE, Langenbach R, Trzaskos JM and Dey SK (1997b) Multiple female reproductive failures in cyclooxygenase 2deficient mice Cel/ 91 197-208

Lim H, Das SK and Dey SK (1998) erbB genes in the mouse uterus: cellspecific signaling by epidermal growth factor (EGF) family of growth factors during implantation Developmental Biology 204 97-110

Lyons I, Parsons L, Hartley L, Li R, Andrews J, Robb L and Harvey R (1995) Myogenic and morphogenetic defects in the heart tubes of murine 
embryos lacking the homeobox gene Nkx2-5. Genes and Development 9 1654-1666

Morris JC, Neben S, Bennett F et al. (1996) Molecular cloning and characterization of murine interleukin-11 Experimental Hematology 24 1369-1376

Nandurkar HH, Hilton DJ, Nathan P, Willson T and Begley CG (1996) The human IL-11 receptor requires gp130 for signalling: demonstration by molecular cloning of the receptor Oncogene 12 585-593

Opal SM, Jhung JW and Keith JC (1998) Recombinant human interleukin11 in experimental Pseudomonas aeruginosa sepsis in immunocompromised animals Journal of Infectious Diseases 178 1205-1208

O'Shea JD, Kleinfeld RG and Morrow HA (1983) Ultrastructure of decidualization in the pseudopregnant rat American Journal of Anatomy $166271-298$

Paul SR, Bennett F, Calvetti JA et al. (1990) Molecular cloning of a cDNA encoding interleukin 11, a stromal cell-derived lymphopoietic and hematopoietic cytokine Proceedings of the National Academy of Sciences USA $877512-7516$

Peterson RL, Wang L, Albert L, Keith JC, Jr and Dorner AJ (1998) Molecular effects of recombinant human interleukin-11 in the HLA-B27 rat model of inflammatory bowel disease Laboratory Investigation 78 1503-1512

Psychoyos A (1973) Endocrine control of egg implantation. In Handbook of Physiology pp 187-215 Ed. RO Greep. American Physiological Society, Washington DC

Quesniaux VF, Mayer P, Liehl E, Turner K, Goldman SJ and Fagg B (1993) Review of a novel hematopoietic cytokine, interleukin-11 International Reviews of Experimental Pathology 34 (A) 205-214

Redlich CA, Gao X, Rockwell S, Kelley M and Elias JA (1996) IL-11 enhances survival and decreases TNF production after radiationinduced thoracic injury Journal of Immunology 157 1705-1710

Robb L, Hilton DJ, Willson TA and Begley CG (1996) Structural analysis of the gene encoding the murine interleukin-11 receptor $\alpha$-chain and a related locus Journal of Biological Chemistry 271 13 754-13 761

Robb L, Hilton DJ, Brook-Carter PT and Begley CG (1997) Identification of a second murine interleukin-11 receptor alpha chain gene (IL11Ra2) with a restricted pattern of expression Genomics 40 387-394
Robb L, Li R, Hartley L, Nandurkar H, Koentgen F and Begley CG (1998) Infertility in female mice lacking the receptor for interleukin 11 is due to a defective uterine response to implantation Nature Medicine 4 303-308

Schwertschlag US, Trepicchio WL, Dykstra KH, Keith JC, Turner KJ and Dorner AJ (1999) Hematopoietic, immunomodulatory and epithelial effects of interleukin-11 Leukemia 13 1307-1315

Shen MM and Leder P (1992) Leukemia inhibitory factor is expressed in the preimplantation uterus and selectively blocks primitive ectoderm formation in vitro. Proceedings National Academy of Sciences USA 89 8240-8244

Song H, Lim H, Das SK, Paria BC and Dey SK (2000) Dysregulation of EGF family of growth factors and COX-2 in the uterus during the preattachment and attachment reactions of the blastocyst with the luminal epithelium correlates with implantation failure in LIF-deficient mice Molecular Endocrinology 14 1147-1161

Teshima T, Hill GR, Pan L, Brinson YS, van den Brink MR, Cooke KR and Ferrara JL (1999) IL-11 separates graft-versus-leukemia effects from graft-versus-host disease after bone marrow transplantation Journal of Clinical Investigation 104 317-325

Waxman AB, Einarsson O, Seres T, Knickelbein RG, Homer R, Warshaw JB, Johnston R and Elias JA (1999) Targeted lung expression of interleukin-11 enhances murine tolerance of $100 \%$ oxygen and diminishes hyperoxia-induced DNA fragmentation Chest 116 8S-9S

Yonemura Y, Kawakita M, Masuda T, Fujimoto K and Takatsuki K (1993) Effect of recombinant human interleukin-11 on rat megakaryopoiesis and thrombopoiesis in vivo: comparative study with interleukin-6 British Journal of Haematology 84 16-23

Received 22 March 2001.

First decision 17 May 2001.

Accepted 7 June 2001. 